\title{
Resource-efficient purification of acidic multi-metal process water by means of anionic nanofibrillated cellulose
}

\section{Venäläinen, Salla H.}

2018-06-01

Venäläinen , S H \& Hartikainen , H 2018 , ' Resource-efficient purification of acidic multi-metal process water by means of anionic nanofibrillated cellulose ' , Journal of Cleaner Production, vol. 185 , pp. 516-522 . https://doi.org/10.1016/j.jclepro.2018.03.096

http://hdl.handle.net/10138/313478

https://doi.org/10.1016/j.jclepro.2018.03.096

cc_by_nc_nd

acceptedVersion

Downloaded from Helda, University of Helsinki institutional repository.

This is an electronic reprint of the original article.

This reprint may differ from the original in pagination and typographic detail.

Please cite the original version. 
Resource-efficient purification of acidic multi-metal process water by means of anionic nanofibrillated cellulose

\author{
Salla $H$. Venäläinen $\mathrm{a}^{*}$ \\ aUniversity of Helsinki, P.O. Box 56, 00014 University of Helsinki, Finland. \\ E-mail: salla.venalainen@helsinki.fi \\ Tel. +358407552135 \\ ${ }^{*}$ Corresponding author
}

Helinä Hartikainen ${ }^{b}$

bUniversity of Helsinki, P.O. Box 56, 00014 University of Helsinki, Finland.

E-mail: helina.hartikainen@helsinki.fi

Tel. +358407084373 


\begin{abstract}
Treatment of acidic mining water (MW) with industrial minerals and alkaline chemicals requires utilisation of unrenewable raw materials and produces disposable inorganic sludges of no further use. We investigated the efficiency of bio-based anionic nanofibrillated cellulose (NFC) to purify authentic MW high in metals and sulphate. In a short-term (10 min) adsorption experiment, highly acidic $(\mathrm{pH} 3.2)$ multi-metal process water was treated with anionic NFC gels differing in their consistency $(1.1 \%, 1.4 \%$ and $1.8 \% \mathrm{w} / \mathrm{w})$ at three sorbent-to-solution ratios.
\end{abstract}

To unravel the purification efficiency of the NFC gels, MW was treated stepwise with a set of fresh NFC gels in three sequential batches. Each treated solution was filtrated before $\mathrm{pH}$ measurement and analysis for the NFC-induced changes in the metal and sulphate concentrations. All NFC gels efficiently co-adsorbed metals and sulphate and decreased the acidity of MW. Depending on the dosage, a triplicated treatment with the NFC gels removed as much as $32-75 \%$ of metal cations and $34-75 \%$ of sulphate anions. The retention of metals highly exceeded the amount of carboxyl groups in the sorbent. Thus, we concluded that, instead of electrostatic adsorption, the retention took place through formation of covalent metal-NFC complexes. The subsequent surplus in positive total charge formed on the NFC-surface, in turn, enabled electrostatic co-adsorption of sulphate anions. The mutual interactions between cellulose nanofibrils in the NFC gel weakened with decreasing consistency, which promoted the accessibility of the sorption sites. This improved the purification efficiency while decreasing the demand for cellulosic raw material. We concluded that anionic NFC could potentially serve as a multifunctional and resource-efficient purification agent in the treatment of acidic process waters of high ionic strength. Ideally, the elements retained could be liberated and recycled elsewhere.

\title{
Keywords
}

Water purification; mining; co-adsorption; metals; sulphate 


\section{Abbreviations and symbols}

NFC, Nanofibrillated cellulose; MW, Mining water; AMD, Acid mine drainage; CN, Cellulose nanomaterial; PLS, Pregnant leaching solution; DM, Dry matter; EC, Electrical conductivity; B1, First batch treatment; B2, Second batch treatment; B3, Third batch treatment; $\mathrm{C}_{0}$, Concentration in the control sample; $C_{B X}$, Concentration after first $(X=1)$, second $(X=2)$ or third $(X=3)$ batch treatment; $\Sigma$ Cations, Total concentration of cations; NFC1.1, Nanofibrillated cellulose gel containing $1.1 \%$ dry matter; NFC1.4, Nanofibrillated cellulose gel containing 1.4\% dry matter; NFC1.8, Nanofibrillated cellulose gel containing $1.8 \%$ dry matter

\section{Introduction}

Various industrial activities, such as chemical and galvanic industries, as well as scrubbing of flue gases in power plants, produce acidic effluents rich in sulphate $\left(\mathrm{SO}_{4}{ }^{2-}\right)$ and often high in soluble metals and metalloids toxic to biota in high concentrations (Johnson, 2000). The main source of these kinds of effluents is mining industry. In abandoned mines or mine waste disposal sites, there is also a risk that the water draining exposing mineral deposits lead to formation of acidic runoff water rich in metals, referred to as acid mine drainage (AMD) (Johnson \& Hallberg, 2005).

The acidity of the mining waters (MWs) originates primarily from the oxidation of iron (Fe) sulphides, e.g. pyrite $\left(\mathrm{FeS}_{2}\right)$, or chalcopyrite $\left(\mathrm{CuFeS}_{2}\right)$ abundant in most metal sulphide deposits (Banks et al., 1997; Johnson, 2014). In a complex cycle of microbially catalysed reactions, protons $\left(\mathrm{H}^{+}\right)$and sulphate ions $\left(\mathrm{SO}_{4}{ }^{2-}\right)$ are produced according to Eq. 1 (e.g. Banks et al., 1997; Johnson \& Hallberg, 2005):

$4 \mathrm{FeS}_{2}+14 \mathrm{H}_{2} \mathrm{O}+15 \mathrm{O}_{2} \rightarrow 4 \mathrm{Fe}(\mathrm{OH})_{3}+8 \mathrm{SO}_{4}{ }^{2-}+16 \mathrm{H}^{+}$

In active metal mines, acidic effluents are neutralised by using industrial minerals or alkaline chemicals to reduce the risks they pose to the environment. Typical neutralisation agents are calcium or magnesium carbonates $\left(\mathrm{CaCO}_{3}\right.$ or $\left.\mathrm{MgCO}_{3}\right)$, oxides $(\mathrm{CaO}$ or $\mathrm{MgO})$, or hydroxides $\left(\mathrm{Ca}(\mathrm{OH})_{2}\right.$ or $\left.\mathrm{Mg}(\mathrm{OH})_{2}\right)$ as well as sodium hydroxide $(\mathrm{NaOH})$ or carbonate $\left(\mathrm{Na}_{2} \mathrm{CO}_{3}\right)$ (Coulton et al., 2003; Johnson 
\& Hallberg, 2005). In this treatment, the metals precipitate as oxides or (hydr)oxides and sediment out of the solution. Simultaneous aeration or addition of oxidising chemicals or flocculants further promote the precipitation (Coulton et al., 2003; Johnson, 2014). Sludge disposal inevitably leads to loss of valuable metals and industrial minerals from the material cycle, which increases the demand for mining of virgin rock raw materials. Thus, more efficient procedures to recover and recycle elements in mining industry are needed to improve its sustainability and profitability.

Acidic leachates from sludge disposal sites pose serious risks of environmental hazards. The immediate deleterious effects are attributable to the toxicity of many soluble metals and metalloids to aquatic organisms (Gerhardt, 1993). For instance, reduced ferrous iron ( $\left.\mathrm{Fe}^{2+}\right)$, typically abundant in AMD, is acutely toxic (Vuori, 1995). After being gradually oxidised to the less toxic ferric form, $\mathrm{Fe}^{3+}$ $\left(\mathrm{pK}_{\mathrm{a}}\right.$ value as low as 2.2 (Lindsay, 1979 p. 130)) undergoes hydrolysis and precipitates as a hydroxide and produces acidity according to Eq. 2:

$\mathrm{Fe}^{3+}+3 \mathrm{H}_{2} \mathrm{O} \rightarrow \mathrm{Fe}(\mathrm{OH})_{3}+3 \mathrm{H}^{+}$

Moreover, if the hydrolysis-derived acidity overcomes the buffering capacity of bicarbonate in the recipient water, its $\mathrm{pH}$ will decrease. This promotes the solubility of toxic heavy metals and reduces the diversity of species and habitats (Gray, 1997). It also favours the weathering of aluminium (Al) silicates and other minerals and, consequently, the release of metals from their structures (Johnson, 2003). Furthermore, in freshwater systems the elevated salinity due to AMD also adversely affects the aquatic biota (Nielsen et al., 2003).

Developing the mining industry towards a circular economy business model and improving its resource efficiency calls for alternative water purification methods that could (a) reduce the demand for mining of virgin non-renewable raw materials and (b) decrease the production of unusable waste. Biodegradable materials made of renewable natural resources may provide an environmentally and 
economically sound alternative to the sludge-generating alkaline chemicals traditionally used in MW treatment.

Cellulose is globally regarded as the most abundant biopolymer, as it is a constituent in wood, plant, tunicate, algae, and bacteria. Utilisation of its nano- or microscale derivatives (referred to as nanofibrillated, nanofibrillar or nanofibril celluloses, cellulose nanofibrils, microfibrillated or microfibrillar celluloses, cellulose microfibrils, and cellulose nanocrystals etc.) as adsorbents in water treatment technologies is gaining interest. Cellulose nanomaterials (CNs) are environmentally inert and low in cost. Furthermore, CNs can be chemically modified to render them anionic or cationic and, thus, able to retain positively or negatively charged elements (Carpenter et al., 2015).

There are several studies on the sorption of heavy metals and/or other cations from solutions of pure chemicals by anionic CNs (e.g. Saito \& Isogai, 2005; Ma et al., 2012; Hokkanen et al., 2013; Isobe et al., 2013; Yu et al., 2013; Kardam et al., 2014; Liu et al., 2014; Sehaqui et al., 2014; Suopajärvi et al., 2015). To our knowledge, the only study hitherto on the retention of $\mathrm{SO}_{4}{ }^{2-}$ from a pure salt solution was carried out by Sehaqui et al. (2016) using cationic CNs. Furthermore, most of the previous sorption experiments with $\mathrm{CNs}$ have been performed by using relatively dilute model solutions. The $\mathrm{pH}$ of the ambient solutions is often adjusted to a level that favours the formation of a desired surface charge on the sorbent (e.g. deprotonation of carboxyl groups) and/or the prevalence of the contaminant species most susceptible to electrostatic adsorption. Industrial effluents, however, typically have a low $\mathrm{pH}$ and high ionic strength. This means that the concentrations of anion and cation species (including protons) competing for the same sorption sites are high. Therefore, their co-adsorption from the solution is a prerequisite to obtain a satisfactory purification result. 
Our previous study revealed that (1) anionic nanofibrillated cellulose (NFC) gel simultaneously retains both metal and $\mathrm{SO}_{4}{ }^{2-}$ ions from authentic acidic $\mathrm{MW}$ and (2) the retention capacity increases with decreasing dry matter (DM) content of the NFC gel (Venäläinen \& Hartikainen, 2017a). In this study, we took a step forward and investigated the utilisation potential of anionic NFC in MW treatment from a more practical point of view. Our aim is (a) to unravel the actual MW purification efficiency of anionic NFC gel and (b) to assess its potential to act as a resource-efficient sorbent in real-life treatment of acidic MW. The working hypotheses are that (a) anionic NFC simultaneously removes metal and $\mathrm{SO}_{4}{ }^{2-}$ ions from acidic $\mathrm{MW}$ and, thus, reduces the need of unrenewable carbonate materials or inorganic chemicals in MW treatment and (b) the purification efficiency of anionic NFC increases with increasing NFC dosages and with repeated treatment cycles.

In the present short-term adsorption experiment, we investigated the efficiency of anionic NFC to coadsorb metal cations ( $\mathrm{Fe}, \mathrm{Al}$, manganese $(\mathrm{Mn})$, nickel $(\mathrm{Ni}), \mathrm{Na}$, and $\mathrm{Mg}$ ) and $\mathrm{SO}_{4}{ }^{2-}$ anions from authentic MW. Based on the strong swelling tendency of NFC in water (Missoum et al., 2013; Liu et al., 2016), we hypothesized that the consistency of the NFC gel affects the strength of hydrogen bonding between the individual nanofibrils and, thus, the accessibility of the sorption sites. Therefore, NFC gels of three different consistencies were investigated as separate sorbents. To assess the impact of sorbent volume and repeated purification cycles on the purification result, all the treatments were carried out at three sorbent-to-solution ratios and in three sequential batches.

\section{Materials and methods}

\subsection{Mining water (MW)}

The MW originated from the Terrafame multimetal mine (previously known as Talvivaara Mining

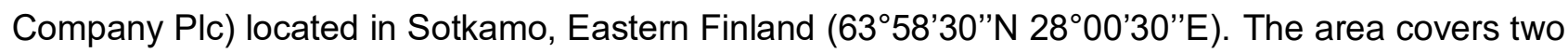
separate polymetallic deposits, Kuusilampi and Kolmisoppi, which are mined for sulphide minerals containing zinc $(\mathrm{Zn}), \mathrm{Ni}$, copper $(\mathrm{Cu})$, and cobalt $(\mathrm{Co})$. Their extraction takes place by heap bioleaching, followed by precipitation of the solubilised $\mathrm{Zn}, \mathrm{Ni}, \mathrm{Cu}$, and $\mathrm{Co}$ in the pregnant leaching 
solution (PLS) as sulphides by means of hydrogen sulphide $\left(\mathrm{H}_{2} \mathrm{~S}\right)$. Part of the remaining effluent (raffinate) is recycled back to the heap bioleaching process. The rest of the raffinate undergoes preliminary treatment with $\mathrm{CaCO}_{3}$ and $\mathrm{O}_{2}$ to remove bulk $\mathrm{Fe}$ as (oxy)hydroxides from the solution before its final neutralisation with $\mathrm{Ca}(\mathrm{OH})_{2}$ to precipitate the residual solubilised metals at $\mathrm{pH} 10$ (Terrafame, 2016, 2018). In 2015, 197000 tons of Ca-containing liming materials and 34000 tons of $\mathrm{NaOH}$ were used in the treatment of mining effluents. These alkali treatments produced 781000 tons of sludge and 8.4 million $\mathrm{m}^{3}$ of water was discharged to the surrounding water systems (Terrafame, 2016).

We carried out our experiments with raffinate subjected to the preliminary precipitation of $\mathrm{Fe}$. It is noteworthy that in the Terrafame mine, the process waters undergo adequate purification before being discharged. Despite the pre-neutralisation process, MW used in this study was still high in Fe as indicated by the orange precipitates formed in the solution upon its exposure to air. The very high electrical conductivity of MW (EC, $20 \mathrm{mS} \mathrm{cm}^{-1}$ ) (measured with Mettler Toledo T70 titrator) and the very low $\mathrm{pH}$ (3.2) ( $\mathrm{pH}$ meter Consort $\mathrm{C6010})$ indicated a high concentration of dissolved acidic ions. The MW was analysed for $\mathrm{Fe}, \mathrm{Mn}, \mathrm{Al}, \mathrm{Ni}, \mathrm{Na}, \mathrm{Mg}$, and $\mathrm{S}$ concentrations (method described in Section 2.3.2). Table 1 shows the concentrations.

\subsection{Nanofibrillated cellulose (NFC)}

We received the anionic NFC gel of a consistency (i.e. dry matter content) of $2.8 \%(\mathrm{w} / \mathrm{w})$ from UPM-Kymmene Oyj, where the anionisation and fibrillation of the material had been previously done by TEMPO-mediated oxidation followed by the mechanical dispersion of the anionic pulp. In the oxidation process, the primary alcohols of cellulose are converted to aldehydes and carboxylic acids using $\mathrm{NaClO}$ as a primary oxidant (Saito et al. 2007). The carboxylate content of the anionic pulp (determined by conductometric titration method SCAN-CM 65:02 (Scandinavian Pulp, Paper and Board Testing Committee, 2002)) was $1 \mathrm{mmol} \mathrm{COOH} \mathrm{g}{ }^{-1} \mathrm{DM}$. For the laboratory experiment, the NFC gel was further diluted with Milli- $Q^{\circledR}$ water to form dispersions having consistencies of $1.8 \%$ 
(NFC1.8), 1.4\% (NFC1.4), and 1.1\% (NFC1.1) (w/w) determined as weight loss after drying 10-mL gel samples at $60^{\circ} \mathrm{C}$ for $19 \mathrm{~h}$. In the experiments, the diluted NFC gels were investigated as separate sorbent materials. The thorough incorporation of the added water into the hydration sphere of the NFC was established by centrifugation (3600 rpm, $10 \mathrm{~min}$, Hermle Labortechnik Z $513 \mathrm{~K}$ ) of the diluted samples. The test revealed that all the added water was properly merged into the hydration shells of the NFC fibrils. Thus, the gels contained no loose water that would cause dilution in the MW samples to be treated.

\subsection{Experimental design}

\subsubsection{Experimental set-up}

The potential of the anionic NFCs (NFC1.8, NFC1.4, and NFC1.1) to decrease the metal and $\mathrm{SO}_{4}{ }^{2-}$ concentrations of MW was investigated by means of adsorption tests (Venäläinen \& Hartikainen, 2017b). The experiments were carried out in three sequential batches (B1, B2, and B3) as follows:

1) In the first batch, a set of $50 \mathrm{~mL} \mathrm{MW}$ samples were treated in $110 \mathrm{~mL}$ polypropylene test tubes by injecting NFC gel into them at three different sorbent-to-solution ratios: 1:5, 2:5, or 3:5 V/V (i.e. $10 \mathrm{~mL}, 20 \mathrm{~mL}$, or $30 \mathrm{~mL}$ of NFC gel). To avoid the breakdown of the NFC flocs formed in the reaction between NFC gel and MW, the suspensions were carefully mixed by turning the tubes over twice. After a 10-min reaction time, the suspensions were passed through filter paper (Whatman ${ }^{\circledR}$ type $589 / 3$ ) into plastic bottles (B1).

2) Next, $40 \mathrm{~mL}$ aliquots of the NFC-treated MW samples obtained from the first batch (B1) were collected. Then each filtrated solution was re-treated with a portion of fresh NFC gel at the same sorbent-to-solution ratio (i.e. with $8 \mathrm{~mL}, 16 \mathrm{~mL}$, or $24 \mathrm{~mL}$ of NFC gel) as previously (10min reaction time) (B2)

3) Finally, $30 \mathrm{~mL}$ aliquots of the NFC-treated MW samples obtained from the second batch (B2) were collected and treated with a third set of fresh NFC gels (i.e. with $6 \mathrm{~mL}, 12 \mathrm{~mL}$, or $18 \mathrm{~mL}$ of NFC gel) as previously (10-min reaction time) (B3). 
The MW samples without NFC treatment, but otherwise prepared similarly to the proper samples, served as controls. All the treatments were performed at room temperature with three replicates. Retention of metals or $\mathrm{SO}_{4}{ }^{2-}$ by the filter paper was ruled out by analysing their concentrations in MW before and after the filtration.

\subsubsection{Chemical analyses of MW samples}

All the filtrates as well as the initial MW were analysed for $\mathrm{Fe}, \mathrm{Mn}, \mathrm{Al}, \mathrm{Ni}, \mathrm{Na}, \mathrm{Mg}$, and $\mathrm{S}$ with ICP-OES (Thermo Scientific iCAP 6000). The wavelengths used in the ICP-OES measurement were 238.2 $\mathrm{nm}$ for Fe, $293.9 \mathrm{~nm}$ for $\mathrm{Mn}, 396.1 \mathrm{~nm}$ for Al, $221.6 \mathrm{~nm}$ for Ni, $589.5 \mathrm{~nm}$ for $\mathrm{Na}, 279.5 \mathrm{~nm}$ for $\mathrm{Mg}$, and $182.0 \mathrm{~nm}$ for $\mathrm{S}$. The initial $\mathrm{pH}$ of $\mathrm{MW}$ was very low (3.2). Due to the low $\mathrm{pK}_{\mathrm{a} 2}$ value of $\mathrm{H}_{2} \mathrm{SO}_{4}$ (1.98) (Lindsay, 1979, p. 284), practically all the $S$ in the solution was expected to occur as sulphate $\mathrm{SO}_{4}{ }^{2-}$. To detect any NFC-induced changes in the acidity of $\mathrm{MW}$, the $\mathrm{pH}$ of all filtrates was measured ( $\mathrm{pH}$ meter Consort C6010). During the ICP-OES measurement, the proper operation of the device was controlled by analysing external standards of known concentrations (prepared from ROMIL PrimAg ${ }^{\circledR}$ Certified Reference Materials, AccuStandard ${ }^{\circledR}$ Accutrace Reference Standard and Perkin Elmer ${ }^{\circledR}$ Pure Instrument Calibration Standard) every 20 samples.

The total NFC-induced removal (\%) of all cations (i.e. $\Sigma$ Cations) and $S$ from MW after each batch treatment (B1, B2 and B3) was calculated according to Eq. 3:

$\left[1-\left(\mathrm{C}_{\mathrm{Bx}} / \mathrm{C}_{0}\right)\right] \times 100 \%$

where $\mathrm{C}_{0}$ is the total cation or $\mathrm{S}$ concentration $\left(\mathrm{mmol} \mathrm{L}^{-1}\right)$ in the control sample and $\mathrm{C}_{\mathrm{BX}}$ is the total cation or $\mathrm{S}$ concentration $\left(\mathrm{mmol} \mathrm{L}^{-1}\right.$ ) in $\mathrm{MW}$ after $\mathrm{B} 1$, $\mathrm{B} 2$ or $\mathrm{B} 3$ treatment (i.e. $\mathrm{C}_{\mathrm{B} 1}, \mathrm{C}_{\mathrm{B} 2}$ or $\mathrm{C}_{\mathrm{B} 3}$ ). The total removal (\%) of each individual cation species from MW after a triplicated treatment with NFC was calculated according to Eq. 4: 
$\left[1-\left(\mathrm{C}_{\mathrm{B} 3} / \mathrm{C}_{0}\right)\right] \times 100 \%$

where $\mathrm{C}_{0}$ is the concentration $\left(\mathrm{mmol} \mathrm{L}^{-1}\right)$ of a given cation species in the control sample and $\mathrm{C}_{\mathrm{B} 3}$ is the concentration of the cation $\left(\mathrm{mmol} \mathrm{L}^{-1}\right)$ after the third batch treatment (B3).

\subsection{Statistical analyses}

Concentration of each metal and $\mathrm{SO}_{4}{ }^{2-}$ in $\mathrm{MW}$ determined before and after the NFC treatments was calculated as the average of three replicated subsamples. A standard deviation (SD) was calculated for the concentration of each element as well as for the total cation concentration. Differences between the metal and $\mathrm{SO}_{4}{ }^{2-}$ concentrations in $\mathrm{MW}$ after a triple treatment with $\mathrm{NFC}$ of different consistency (NFC1.8, NFC1.4 and NFC1.1) at sorbent-to-solution ratios of 1:5, 2:5 and 3:5 were tested by one-way analysis of variance using Tukey's test for paired comparisons. Statistical analyses were carried out with SPSS 24.0 for Windows. The statistical significance was determined as $p \leq 0.05$.

\section{Results}

In the first batch treatment with the NFCs, visible Fe precipitates in MW had attached onto the NFC surfaces rendering the NFC flocs orange and the solution light yellow, but clear. A few hours later, however, we detected spontaneous Fe precipitation in the filtrates. Repeated treatment of the filtrates with NFCs restrained the formation of the coloured particles in the filtrates and after the third batch treatment, the particle formation was minor. Sequential treatment of MW with the NFCs gradually elevated the $\mathrm{pH}$ of the filtrate, but the increase was statistically significant only in the samples treated at the solid-to-solution ratios of 2:5 and 3:5 (Table 1). At the highest ratio (3:5), pH of the filtrate increased from 3.2 to $3.6-3.7$. 


\begin{tabular}{|c|c|c|c|c|c|c|c|c|}
\hline Treatment & V:V & $\mathrm{pH}$ & $\mathbf{N i}$ & Al & Mn & $\mathrm{Na}$ & Mg & $\mathrm{Fe}$ \\
\hline None & & $3.2^{\mathrm{a}}$ & $1.4 \pm 0.0$ & $9.3 \pm 0.4$ & $63 \pm 1.6$ & $95 \pm 3.5$ & $163 \pm 5.1$ & $171 \pm 3.7$ \\
\hline \multirow[t]{2}{*}{ NFC1.8 } & $1: 5$ & $3.3^{\mathrm{ab}}$ & $0.9 \pm 0.0(-34)$ & $5.9 \pm 0.1(-37)$ & $42 \pm 0.9(-33)$ & $64 \pm 1.2(-33)$ & $113 \pm 3.8(-31)$ & $116 \pm 2.7(-32)$ \\
\hline & $2: 5$ & $3.4^{b}$ & $0.7 \pm 0.1(-48)$ & $4.3 \pm 0.9(-54)$ & $32 \pm 5.1(-50)$ & $51 \pm 5.6(-46)$ & $85 \pm 12.3(-48)$ & $90 \pm 11.6(-48)$ \\
\hline \multirow[t]{3}{*}{ NFC1.4 } & $1: 5$ & $3.3^{\mathrm{a}}$ & $0.9 \pm 0.0(-32)$ & $5.7 \pm 0.1(-39)$ & $41 \pm 0.7(-35)$ & $62 \pm 1.0(-35)$ & $109 \pm 4.5(-33)$ & $114 \pm 2.1(-33)$ \\
\hline & $2: 5$ & $3.4^{\mathrm{b}}$ & $0.6 \pm 0.0(-55)$ & $3.5 \pm 0.2(-62)$ & $27 \pm 0.9(-57)$ & $44 \pm 1.3(-53)$ & $73 \pm 1.8(-55)$ & $79 \pm 2.6(-54)$ \\
\hline & $3: 5$ & $3.6^{c}$ & $0.4 \pm 0.1(-70)$ & $2.1 \pm 0.4(-78)$ & $18 \pm 2.2(-71)$ & $33 \pm 2.1(-66)$ & $49 \pm 6.6(-70)$ & $54 \pm 6.5(-69)$ \\
\hline NFC1.1 & $3: 5$ & $3.7^{c}$ & $0.4 \pm 0.0(-74)$ & $1.7 \pm 0.1(-82)$ & $16 \pm 0.5(-75)$ & $28 \pm 0.3(-70)$ & $42 \pm 2.9(-74)$ & $46 \pm 1.3(-73)$ \\
\hline
\end{tabular}

Table 1. Concentrations of different cation species \pm SD and pH of MW before and after a triplicated treatment with NFCs of different consistencies (NFC1.8, NFC1.4, and NFC1.1) at sorbent-to-solution ratios of 1:5, 2:5, and 3:5. The NFC-induced decrement (\%) in the concentration of each cation species is given in brackets. Different letters in the superscript indicate statistically significant differences $(p \leq 0.05)$ in the $\mathrm{pH}$ between the various treatment combinations. 
3.1 Changes in cation and $\mathrm{SO}_{4}{ }^{2-}$ concentrations in $\mathrm{MW}$ treated with $\mathrm{NFC}$ gels of different consistencies

In untreated MW, the abundance of the metals (on molar basis) followed the order: $\mathrm{Fe}>\mathrm{Mg}>\mathrm{Na}>$ $\mathrm{Mn}>\mathrm{Al}>\mathrm{Ni}$ (Table 1). The total concentration of cations (LCations) amounted to $500 \mathrm{mmol} \mathrm{L}^{-1}$ and practically equalled that of $\mathrm{SO}_{4}{ }^{2-}\left(510 \mathrm{mmol} \mathrm{L}^{-1}\right)$. All NFC treatments efficiently lowered the concentration both of cations and $\mathrm{SO}_{4}{ }^{2-}$ in $\mathrm{MW}$ (Fig. 1). Interestingly, the most diluted NFC gel (NFC1.1) lowered the total cation concentration $14-30 \%$ and the $\mathrm{SO}_{4}{ }^{2-}$ concentration $12-26 \%$ more than the equivalent volume of the thickest NCF gel (NFC1.8).

Increasing the sorbent-to-solution ratio from $1: 5$ to $2: 5$ and $3: 5$ significantly enhanced the element removal from MW. Tripling the sorbent volume doubled the retention of cations and $\mathrm{SO}_{4}{ }^{2-}$ (Fig. 1). The total removal of elements, however, was most efficient when the NFC treatments were carried out sequentially (in the batches B1, B2 and B3). In fact, the triplicated treatment at a sorbent-tosolution ratio of $1: 5$ lowered the concentration of all ions more efficiently than a single treatment at a ratio of 3:5 (Fig. 1). The best purification result was obtained when MW was treated in three sequential batches with the most diluted NFC 1.1 at the highest sorbent-to-solution ratio (3:5). This combination simultaneously removed $73 \%$ of the total amount of cations and $75 \%$ of $\mathrm{SO}_{4}{ }^{2-}$ from $\mathrm{MW}$ (Fig. 1). As for the individual elements, the decrease was most pronounced in the Al concentration that diminished $73 \%, 78 \%$, and $82 \%$ upon three sequential treatments with NFC1.8, NFC1.4, and NFC1.1 (Table 1).

\section{Discussion}

Previous studies on the cation retention by various anionic $\mathrm{CNs}$ have concentrated on the capacity of the materials to retain single contaminants rather than on their potential to act as purification agents in the treatment of real-life multi-element industrial effluents (e.g. Hokkanen et al., 2013; Isobe et al., 2013; Yu et al., 2013; Kardam et al., 2014; Sehaqui et al., 2014; Suopajärvi et al., 2015). 
In these theoretically oriented experiments, the initial cation concentrations in the solutions have been rather low $\left(0.005\right.$ to $\left.17.9 \mathrm{mmol} \mathrm{L}^{-1}\right)$ and the reaction times relatively long, typically ranging from $20 \mathrm{~h}$ up to $3 \mathrm{~d}$. These experimental designs have produced maximum cation removals as high as $85.5-100 \%$.

Our initial cation concentration in the authentic MW was 28-100 000 -fold higher than in the previously used solutions. Furthermore, our reaction time was decisively shorter (10 min). Owing to these fundamental differences in the experimental designs, our results provide a novel and practical starting point to intensify the purification of industrial effluents. Considering the extremely high initial concentrations of elements in our MW, the cation removal maxima (64-73\%) obtained with the triplicated treatment with anionic NFC gels, is substantial.

\subsection{Retention mechanisms of cations and $\mathrm{SO}_{4}{ }^{2-}$ by the NFC}

Several researchers have reported that the principal mechanism responsible for the retention of cations by anionic $\mathrm{CNs}$ is electrostatic adsorption onto the deprotonated functional groups (e.g. carboxyl, -COOH) on the CN surfaces (e.g. Ma et al., 2012; Hokkanen et al., 2013; Kardam et al., 2014; Suopajärvi et al., 2015). To encourage the deprotonation of the surfaces, previous studies adjusted the $\mathrm{pH}$ of the ambient solution to 5-6.5. In our study, however, the authentic mining water was very acidic ( $\mathrm{pH} 3.2-3.7)$. Thus, it can be concluded that the carboxyl groups $\left(\mathrm{pK}_{\mathrm{a}} \sim 5\right)$ mainly remained protonated and rendered the CN surface electrostatically neutral or positively charged. Thus, they were unable to retain cations by means of electrostatic attractions.

Furthermore, since our authentic MW was very acidic, substitution of the protons in the functional groups of the NFC by the cations in the solution phase would have lowered its $\mathrm{pH}$. We found, however, that $\mathrm{pH}$ of $\mathrm{MW}$ increased from 3.2 up to 3.6-3.7 concomitantly with promoted cation retention. This finding supports our earlier observation indicating that, instead of cation exchange or 
electrostatic adsorption, the retention of metals took place though complex or chelate formation (Venäläinen \& Hartikainen, 2017a). In this type of reaction, a ligand with a lone electron pair enters the electron shells of a metal cation and substitutes a $\mathrm{OH}^{-}$or $\mathrm{OH}_{2}$ ligand in its co-ordination sphere. Hence, a covalent bond is formed between the metal and the ligand, liberating the substituted group to the solution.

It can also be concluded that the high ionic strength of MW suppressed the hydration spheres of the metal ions in the solution phase. This, in turn, favoured the access of the ligand (anionic NFC) into the electron shells of the cations and the formation of metal-NFC complexes. The hydroxyl $(-\mathrm{OH})$, aldehyde $(-\mathrm{COH})$, and carboxyl $(-\mathrm{COOH})$ groups of the NFC provided lone electron pairs for the formation of metal-ligand complexes. The affinity of these functional groups is particularly high for $\mathrm{Al}^{3+}$ and $\mathrm{Fe}^{3+}$. This and the relatively low initial $\mathrm{Al}$ concentration in the untreated MW explain why the NFC treatments removed relatively more efficiently Al than the other cations.

The low initial $\mathrm{pH}$ of $\mathrm{MW}$ (3.2) indicates that the predominant soluble $\mathrm{Fe}$ species were $\mathrm{Fe}^{3+}$ and $\mathrm{Fe}(\mathrm{OH})^{2+}\left(\mathrm{pK}_{\mathrm{a} 1}\right.$ of $\mathrm{Fe}^{3+}$ is 2.19 , Lindsay, 1979, p. 130). Furthermore, the anionic NFCs elevated the solution $\mathrm{pH}$. This response can be attributed to the organic ligand that substituted the $\mathrm{OH}^{-}$group in the co-ordination sphere of $\mathrm{Fe}(\mathrm{OH})^{2+}$ and released it into the solution. Subsequently, the efficient removal of the soluble Fe species lowered their concentration in $\mathrm{MW}$ and, thus, impeded their acid-producing hydrolysis. This is supported by the diminished formation of Fe precipitates in the filtrates undergoing NFC treatments. In other words, the anionic NFC retarded the formation of acidity. This reaction pattern further explains the finding that the $\mathrm{pH}$ of the NFC-treated MW increased.

Furthermore, the cation equivalents removed from the solution largely exceeded the moles of the carboxyl groups in the NFC. This finding supports the conclusion that, in addition to electrostatic adsorption, other reaction mechanisms also contributed to the removal of metals in the NFC treatment. Moreover, as our previous paper suggests (Venäläinen \& Hartikainen, 2017b), the 
conductometric titration method used in the determination of the number of $-\mathrm{COOH}$ groups in the undispersed cellulose pulp may underestimate the charge density in the dispersed material. Gelation of the anionic pulp in water decreases the inter- and intra-molecular interactions (e.g. hydrogen bonds) within the cellulose fibrils. Consequently, activity of the $\mathrm{COOH}$-groups can be higher than that estimated in the titration.

The nucleophilic nature of $\mathrm{SO}_{4}{ }^{2-}$ renders it susceptible to be retained electrostatically rather than through complex formation. We recorded, however, that despite its negative surface charge NFC efficiently removed $\mathrm{SO}_{4}{ }^{2-}$ from MW. In terms of electrical charges, the retention of $\mathrm{SO}_{4}{ }^{2-}$ practically equalled the total retention of cations. This suggests that the driving force in the sorption was the surplus of positive charge formed onto the anionic NFCs. It enabled a concomitant electrostatic retention of $\mathrm{SO}_{4}{ }^{2-}$ anions onto the NFC surface. Even though the MW in our study was initially very high in $\mathrm{SO}_{4}^{2-}$ (over $500 \mathrm{mmol} \mathrm{L}^{-1}$ ), its maximum retention rates were remarkably high (67-75\%). Recently, Sehaqui et al. (2016) reported that in an overnight reaction a cationic CN gel (consistency of $0.3 \%$, modified by quaternary ammonium, a sorbent-to-solution ratio of $1: 2$ ) removed $27.5 \%$ of $\mathrm{SO}_{4}{ }^{2-}$ from a dilute $\left(3 \mathrm{mmol} \mathrm{L}{ }^{-1}\right)$ salt solution (chemical not given). The sorption increased with the increase in $\mathrm{N}^{+}$-derived positive charges.

It is noteworthy that in this study the triplicated treatment of MW with the NFC gels substantially (60$70 \%$ ) reduced the concentration of $\mathrm{Na}^{+}$. This monovalent cation has a small ionic radius and, consequently, a high hydration tendency. That is why it is very weak in competition with di- or trivalent cations for negatively charged (ad)sorption sites and is also reluctant to be precipitated. This alkali metal is regarded as a weak complexing cation as indicated by the low stability constants of $\mathrm{Na}$ EDTA (log K 1.8, Smith \& Martell, 1987). The formation of metal-ligand complexes onto the anionic NFCs explains the efficient retention of transition metals, while the retention mechanism of $\mathrm{Na}$ is unclear. Its removal can be attributed to the ability to form a weak aqueous complex with strongly solvating $\mathrm{SO}_{4}{ }^{2-}$. Buchner et al. (1999) concluded that the $\mathrm{NaSO}_{4}{ }^{-}$complex is either doubly solventseparated with two water molecules, or it is solvent-shared with only one water molecule between 
the ions. They showed that the solvent-shared species predominates at high concentrations. Thus, it is possible that in our study the high ionic strength of MW suppressed the hydration spheres of $\mathrm{Na}^{+}$ and $\mathrm{SO}_{4}{ }^{2-}$ ions promoting their mutual interaction. Hence, part of $\mathrm{SO}_{4}{ }^{2-}$ ions retained by the anionic NFCs might have taken place as $\mathrm{NaSO}_{4}{ }^{-}$species.

\subsection{Factors affecting the purification efficiency of NFC}

Triplication of the volume of NFC gel obviously increased the number of available sorption sites and, consequently, the retention of cations and $\mathrm{SO}_{4}{ }^{2-}$ anions (Fig. 1). It is noteworthy, however, that the ion concentrations did not diminish in accordance with increasing dosages of NFC gels. Moreover, treatment of $\mathrm{MW}$ with NFC1.1 of low consistency removed cations and $\mathrm{SO}_{4}{ }^{2-}$ more efficiently than equal volumes of NFC gels of higher consistencies (1.4 and 1.8). These findings indicate that the retention of ions was more attributable to the accessibility of the sorption/retention sites rather than to their absolute amount in the sorbent.

It can be concluded that when the consistency of the NFC gel is high, the functional groups on the surface of adjacent cellulose nanofibrils interact with each other by hydrogen bonds. These interactions cluster the individual fibrils (Schmid \& Klingenberg, 2000) and, consequently, reduce their accessibility for cation retention. Similarly, when the sorbent-to-solution ratio is high, the individual fibrils are susceptible to mutual interactions. This conclusion is supported by the finding that at a low sorbent-to-solution ratio of 1:5, a triple treatment with NFCs of any consistency removed all ions more efficiently than did a single treatment with the same sorbent at a higher ratio of 3:5.

\subsection{Implementation of anionic NFC in purification of mining waters in practice}

The amount of neutralisation agents required in the purification process of mining waters largely depends on the nature of the effluents. In other words, further studies with authentic process waters should be carried out. It can be concluded, however, that a preliminary treatment of acidic mining 
effluents with anionic NFC would significantly decrease the need of lime and alkaline chemicals to precipitate metals and, consequently, the formation of gypsum and hydroxide sludges.

The rapid co-adsorption of cations and $\mathrm{SO}_{4}{ }^{2-}$ from $\mathrm{MW}$ and the substantial increase in their retention upon the repeated treatment with the fresh anionic NFCs indicate that the best purification outcome is obtainable by constantly feeding the sorbent to the effluent at a moderate ratio and reclaiming it after a short reaction time. Ideally, the elements recovered by the anionic NFC could be liberated from the sorbent (e.g. by incineration of the element-enriched NFC) and recycled elsewhere. Another option could be to release the adsorbed elements by chemical treatment and to reuse the regenerated sorbent in the process. The pivotal point is to trap the dissolved elements from a large water volume into a more easily handled form. Hitherto, the regeneration of cation-enriched CNs is proven to be plausible in the laboratory e.g. by acid and/or ultrasonic treatment (Hokkanen et al., 2013; Isobe et al., 2013; Sehaqui et al., 2014) or $\mathrm{NaCl}$ treatment (Yu et al., 2013). It is likely, that the regeneration process largely depends on the type and strength of chemical bonds formed between the $\mathrm{CNs}$ and the retained element. More thorough studies on the reaction mechanisms of regeneration are, however, required to develop applications for use in the industrial scale.

\section{Conclusions}

We revealed that the treatment of very acidic authentic MW of high ionic strength with anionic NFC efficiently and quickly reduces its metal ( $\mathrm{Fe}, \mathrm{Al}, \mathrm{Mn}, \mathrm{Ni}, \mathrm{Na}$, and $\mathrm{Mg}$ ) and $\mathrm{SO}_{4}{ }^{2-}$ concentrations. In cation retention, the primary mechanism is the formation of covalent metal-ligand complexes between the metal ions and the cellulose nanofibrils. The sorbed multivalent cations render the NFC surface positively charged, which enables the electrostatic co-adsorption of the $\mathrm{SO}_{4}{ }^{2-}$ anion. Dilution of the NFC gel to a point of maximum incorporation of added water diminishes the mutual interactions between the individual nanofibrils and, consequently, improves the purification efficiency by promoting the accessibility of sorption sites. 
The overall retention of cations and $\mathrm{SO}_{4}{ }^{2-}$ onto the anionic NFC gel rises when the sorbent-to-solution ratio is high. In suspensions overcrowded with NFC, however, part of the sorption sites remain untapped. The best purification result will be obtained when MW is subjected to several short-term treatments in sequential batches with fresh NFC portions at a moderate sorbent-to-solution ratio. The results indicate that anionic NFC is a potential purification agent in the treatment of acidic mining effluents. Being manufactured from degradable and renewable materials and consisted over $98 \%$ of water, NFC would be an environmentally sound substitute or supplementary agent for the use of traditional industrial minerals and alkaline chemicals used in the treatment of acidic mining effluents.

\section{Acknowledgements}

We thank UPM-Kymmene Oyj for preparing and providing the cellulose nanomaterial for this research and Terrafame Group Ltd. for the process water samples. This study was financially supported by Maj and Tor Nessling Foundation (grant number 201600101), K.H. Renlund Foundation (grant number 28312) and Maa- ja vesitekniikan tuki ry (grant number 33352). Conflicts of interest: none.

\section{References}

Banks, D., Younger, P.L., Arnesen, R-T., Iversen, I.R. \& Banks, S.P. 1997. Mine-water chemistry: the good, the bad and the ugly. Environ. Geol. 32: 157-174.

Buchner, R., Capewell, S.G., Hefter, G. \& May, P.M. 1999. Ion-pair and solvent relaxation processes in aqueous $\mathrm{Na}_{2} \mathrm{SO}_{4}$ solutions. J. Phys. Chem. B 103: 1185-1192.

Carpenter, A.W., de Lannoy, C-F. \& Wiesner, M.R. 2015. Cellulose nanomaterials in water treatment technologies. Environ. Sci. Technol. 49: 5277-5287.

Coulton, R., Bullen, C. \& Hallet, C. 2003. The design and optimisation of active mine water treatment plants. Land Contam. Reclamat. 11: 273-279. 
Gerhardt, A. 1993. Review of impact of heavy metals on stream invertebrates with special emphasis on acid conditions. Water Air Soil Pollut. 66: 289-314.

Gray, N.F., 1997. Environmental impact and remediation of acid mine drainage: a management problem. Environ. Geol. 30: 62-71.

Hokkanen, S., Repo, E. \& Sillanpää, M. 2013. Removal of heavy metals from aqueous solutions by succinic anhydride modified mercerized nanocellulose. Chem. Eng. J. 223: 40-47.

Isobe, N., Chen, X., Kim, U-J., Kimura, S., Wada, M., Saito, T. \& Isogai, A. 2013. TEMPO-oxidized cellulose hydrogel as a high-capacity and reusable heavy metal ion adsorbent. J. Hazard. Mater. 260: 195-201.

Johnson, D.B. 2000. Biological removal of sulfurous compounds from inorganic wastewaters. In: Lens, P. \& Hulshoff Pol, L. (Eds). Environmental technologies to treat sulfur pollution: principles and engineering. IWA Publishing, London, UK. pp. 175-206.

Johnson, D.B. 2003. Chemical and microbiological characteristics of mineral spoils and drainage water at abandoned coal and metal mines. Water Air Soil Pollut.: Focus 3: 47-66.

Johnson, D.B. 2014. Recent developments in microbiological approaches for securing mine wastes and for recovering metals from mine waters. Minerals 4: 279-292.

Johnson, D.B. \& Hallberg, K.B. 2005. Acid mine drainage remediation options: a review. Sci. Total Environ. 338: 3-14.

Kardam, A., Rohit, K, Shalini, R., Srivastava, S. \& Srivastava, M.M. 2014. Nanocellulose fibers for biosorption of cadmium, nickel, and lead ions from aqueous solution. Clean Technol. Envir. 16: 385393.

Lindsay, W.L. 1979. Chemical equilibria in soils. John Wiley \& Sons, Inc, USA. 449p.

Liu, P., Sehaqui, H., Tingaut, P., Wichser, A., Oksman, K. \& Mathew, A.P. 2014. Cellulose and chitin nanomaterials for capturing silver ions $\left(\mathrm{Ag}^{+}\right)$from water via surface adsorption. Cellulose $21: 449$ 461. 
Liu, J., Chinga-Carrasco, G., Cheng, F., Xu, W., Willför, S., Syverud, K. \& Xu, C. 2016. Hemicellulose-reinforced nanocellulose hydrogels for wound healing application. Cellulose 23: 3129-3143.

Ma, H., Hsiao, B.S. \& Chu, B. 2012. Ultrafine cellulose nanofibers as efficient adsorbents for removal of $\mathrm{UO}_{2}^{2+}$ in water. ACS Macro Lett. 1: 213-216.

Missoum, K., Belgacem, M.N. \& Bras, J. 2013. Nanofibrillated cellulose surface modification: A review. Materials 6: 1745-1766.

Nielsen, D.L., Brock, M.A., Rees, G.N. \& Baldwin, D.S. 2003. Effects of increasing salinity on freshwater ecosystems in Australia. Aust. J. Bot. 51: 655-665.

Saito, T. \& Isogai, A. 2005. Ion-exchange behavior of carboxylate groups in fibrous cellulose oxidized by the TEMPO-mediated system. Carbohydr. Polym. 61: 183-190.

Saito, T., Kimura, S., Nishiyama, Y. \& Isogai, A., 2007. Cellulose nanofibers prepared by TEMPOmediated oxidation of native cellulose. Biomacromolecules 8: 2485-2491.

Scandinavian Pulp, Paper and Board Testing Committee, 2002. Method SCAN-CM 65:02. Total acidic group content. Stockholm, Sweden. 4 p.

Schmid, C.F. \& Klingenberg, D.J. 2000. Properties of fiber flocs with frictional and attractive interfiber forces. J. Colloid Interface Sci. 226: 136-144.

Sehaqui, H., de Larraya, U.P., Liu, P., Pfenninger, N., Mathew, A.P., Zimmermann, T. \& Tingaut, P. 2014. Enhancing adsorption of heavy metal ions onto biobased nanofibers from waste pulp residues for application in wastewater treatment. Cellulose 21: 2831-2844.

Sehaqui, H., Mautner, A., de Larraya, U.P., Pfenninger, N., Tingaut, P. \& Zimmermann, T. 2016. Cationic cellulose nanofibers from waste pulp residues and their nitrate, fluoride, sulphate and phosphate adsorption properties. Carbohydr. Polym. 135: 334-340. 
Smith, R.M. \& Martell, A.E. 1987. Critical stability constants, enthalpies and entropies for the formation of metal complexes of aminopolycarboxylic acids and carboxylic acids. Sci. Total Environ. 64: $125-147$.

Suopajärvi, T., Liimatainen, H., Karjalainen, M., Upola, H. \& Niinimäki, J. 2015. Lead adsorption with sulfonated wheat pulp nanocelluloses. J. Water Process Eng. 5: 136-142.

Terrafame, 2016. Annual environmental monitoring report 2015. In Finnish. Available from: https://www.terrafame.fi/media/ymparistoraportit/2015/vuosiraportti_2015_osa_i_yhteenveto.pdf Last accessed 11/01/2018.

Terrafame, 2018. Water purification. Available from:

https://www.terrafame.com/environment/environment-water-management/water-purification.html Last accessed 11/01/2018.

Venäläinen, S.H. \& Hartikainen, H. 2017a. Retention of metal and sulphate ions from acidic mining water by anionic nanofibrillated cellulose. Sci. Total Environ. 599-600: 1608-1613.

Venäläinen, S.H. \& Hartikainen, H. 2017b. Anionic nanofibrillated cellulose - a sustainable agent to recover highly soluble salts from industrial effluents. Environ. Technol. Innov. 8: 282-290.

Vuori, K. 1995. Direct and indirect effects of iron on river ecosystems. Ann. Zool. Fenn. 32: 317329.

Yu, X., Tong, S., Ge, M., Wu, L, Zuo, J., Cao, C. \& Song, W. 2013. Adsorption of heavy metal ions from aqueous solutions by carboxylated cellulose nanocrystals. J. Environ. Sci. 25: 933-943. 
(a)

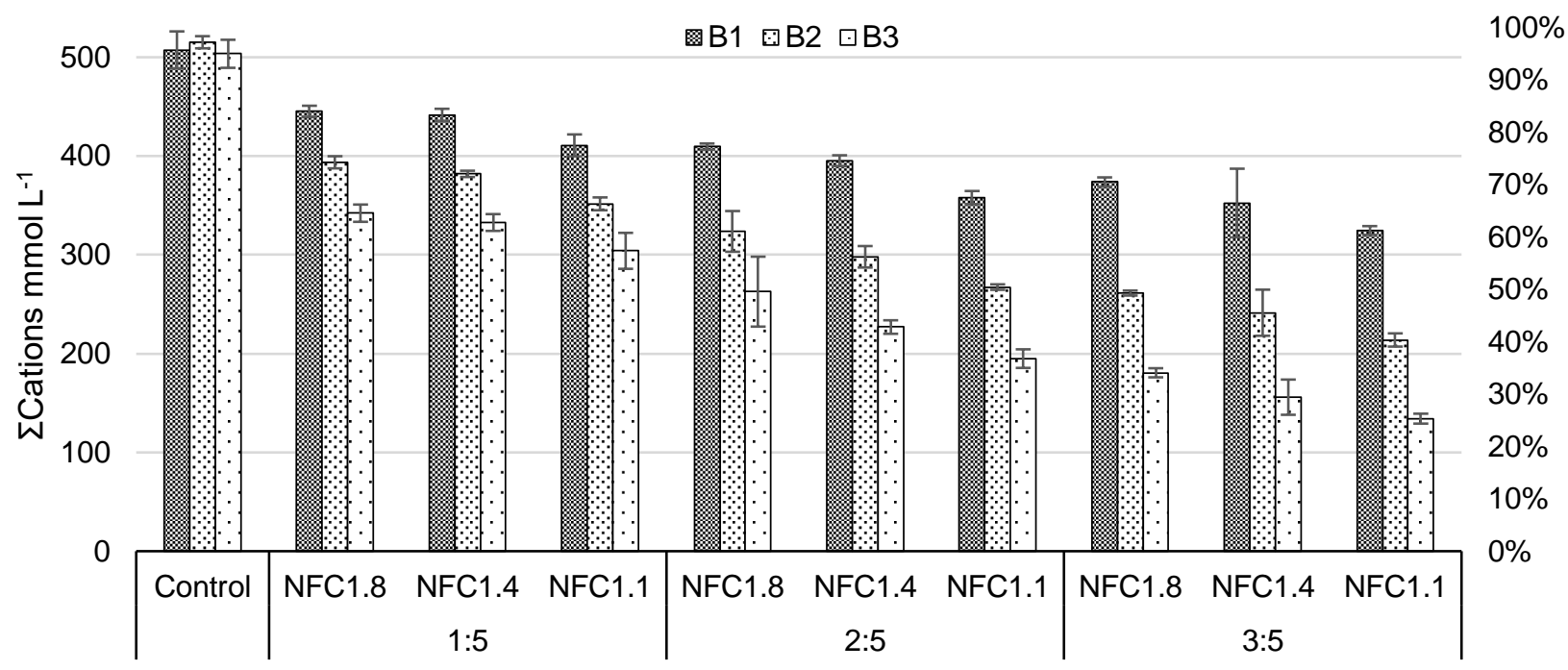

\begin{tabular}{|c|c|c|c|c|c|c|c|c|c|c|}
\hline B1 & & $-12 \%$ & $-13 \%$ & $-19 \%$ & $-19 \%$ & $-22 \%$ & $-29 \%$ & $-26 \%$ & $-31 \%$ & $-36 \%$ \\
\hline B2 & & $-24 \%$ & $-26 \%$ & $-32 \%$ & $-37 \%$ & $-42 \%$ & $-48 \%$ & $-49 \%$ & $-53 \%$ & $-58 \%$ \\
\hline B3 & & $-32 \%$ & $-34 \%$ & $-40 \%$ & $-48 \%$ & $-55 \%$ & $-61 \%$ & $-64 \%$ & $-69 \%$ & $-73 \%$ \\
\hline & $a$ & $b$ & $b$ & $b c$ & $\mathrm{~cd}$ & de & ef & $f$ & $\mathrm{fg}$ & $\mathrm{g}$ \\
\hline
\end{tabular}

(b)

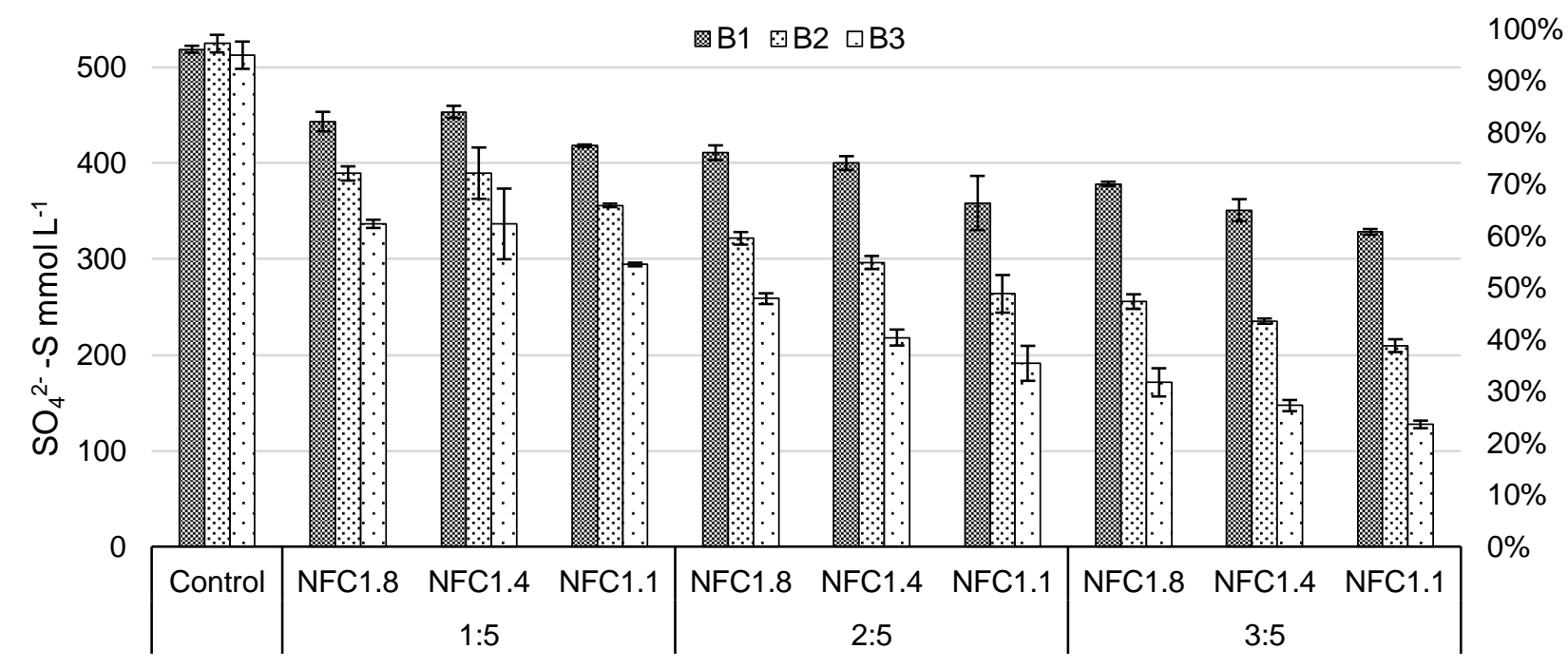

\begin{tabular}{|c|c|c|c|c|c|c|c|c|c|c|}
\hline B1 & & $-15 \%$ & $-13 \%$ & $-19 \%$ & $-21 \%$ & $-23 \%$ & $-31 \%$ & $-27 \%$ & $-32 \%$ & $-37 \%$ \\
\hline B2 & & $-26 \%$ & $-26 \%$ & $-32 \%$ & $-39 \%$ & $-44 \%$ & $-50 \%$ & $-51 \%$ & $-55 \%$ & $-60 \%$ \\
\hline B3 & & $-34 \%$ & $-34 \%$ & $-43 \%$ & $-50 \%$ & $-57 \%$ & $-63 \%$ & $-67 \%$ & $-71 \%$ & $-75 \%$ \\
\hline & a & $b$ & $b$ & bc & $\mathrm{cd}$ & de & ef & $\mathrm{fg}$ & gh & $\mathrm{h}$ \\
\hline
\end{tabular}


Fig. 1. (a) Total cation ( $\Sigma$ Cations) and (b) $\mathrm{SO}_{4}{ }^{2-}-\mathrm{S}$ concentrations ( $\mathrm{mmol} \mathrm{L}^{-1}$ ) and their relative (\%) proportions in mining water (MW) before (Control) and after three sequential batch treatments (B1, B2, and B3) with fresh NFC gels of dissimilar consistencies (NFC1.8, NFC1.4, and NFC1.1) at sorbent-to-solution ratios of 1:5, 2:5 and 3:5. Error bars designate the SD of the concentrations. The NFC-induced decrements (\%) in $\Sigma$ Cations and $\mathrm{SO}_{4}{ }^{2-}-\mathrm{S}$ concentrations in $\mathrm{MW}$ in each treatment are listed in the tables below the figures. Different letters below the tables indicate statistically significant differences (Tukey's test, $p \leq 0.05$ ) in the $\Sigma$ Cations or and $\mathrm{SO}_{4}{ }^{2-}-\mathrm{S}$ concentrations after a triplicated treatment with NFC gels of various consistencies at different sorbent-to-solution ratios. 